\title{
Malignant giant solitary fibrous tumour of the mediastinum; masquerading Triton tumour
}

\author{
Arshi Beg ${ }^{1}$, Jeenal Parikh', Amit Janu² and Rajiv Kumar Kaushal ${ }^{1 *}$ (D)
}

\begin{abstract}
Background: Malignant Solitary fibrous tumour (SFT) is an uncommon mesenchymal tumour with aggressive clinical behaviour as compared to its benign counterpart. There are only a handful of reports of extra-pleural malignant SFT arising from the mediastinum.
\end{abstract}

Case presentation: A 68-year-old male, presented with a history of cough and breathlessness for 2 weeks. Computed tomography $(\mathrm{CT})$ scan revealed a large $11.6 \times 11.3 \times 18 \mathrm{~cm}$ anterior mediastinal mass with extension to right hemithorax. The patient underwent excision of the mass after a biopsy confirmation of mesenchymal tumour. Histological examination of resection specimen revealed a spindle cell tumour with hypo and hypercellular areas, arranged in fascicular, focal storiform and hemangio-pericytomatous vasculature pattern. Moderate to marked nuclear atypia, frequent mitosis and areas of necrosis were noted. On immunohistochemistry $(\mathrm{IHC})$, the tumour cells were positive for CD34, BCl2, MIC2 (dot-like) and focally for S100 and Desmin. Although, the possibility of a malignant peripheral nerve sheath tumour with heterologous rhadomyosarcomatous differentiation (Triton tumour) was considered, however IHC for STAT6 confirmed it to be a malignant SFT. The patient developed recurrence within 1 year after surgery and despite multi-modality treatment (Re-excision, Chemotherapy and Radiotherapy) succumbed within 14 months from point of presentation.

Conclusion: Malignant SFT is a rare aggressive tumour that should be considered as a differential diagnosis in the mediastinum and a broad panel of IHC markers including STAT6 may be required to confirm the diagnosis.

Keywords: Solitary fibrous Tumours, Extra pleural, Mediastinum, Sarcoma, STAT6

\section{Background}

A solitary fibrous tumour (SFT) is an uncommon but well-known intrathoracic fibroblastic tumour of intermediate malignant potential and was originally described as arising in relation to pleura. It is characterized by prominent, staghorn/ hemangiopericytoma like branching, vascular pattern and NAB-STAT6 gene rearrangement (Chick et al. 2013; Demicco et al. 2020). Since its description, numerous reports of extra-pleural SFT have been published (Fletcher et al. 2013; Ronchi et al. 2018).

\footnotetext{
* Correspondence: rajiv.kaushal@gmail.com

${ }^{1}$ Department of Pathology, Tata Memorial Hospital, Homi Bhabha National Institute, Dr Ernest Borges Marg, Parel, Mumbai 400 012, India

Full list of author information is available at the end of the article
}

Approximately $1-8 \%$ of intrathoracic SFT are reported from mediastinum (Ronchi et al. 2018; Den Bakker et al. 2015). Malignant SFTs, characterized by increased cellularity, cellular pleomorphism, mitoses $>4$ per 10 high power fields (HPFs) and necrosis are extremely unusual in the mediastinal region (England et al. 1989). They have relatively aggressive course and inferior diseasespecific survival (De Raet et al. 2008).

We hereby present a rare and diagnostically challenging case of giant malignant SFT of the mediastinum with the expression of a concoction of immunohistochemical (IHC) markers raising a range of differential diagnoses.

(c) The Author(s). 2021 Open Access This article is licensed under a Creative Commons Attribution 4.0 International License, which permits use, sharing, adaptation, distribution and reproduction in any medium or format, as long as you give appropriate credit to the original author(s) and the source, provide a link to the Creative Commons licence, and indicate if changes were made. The images or other third party material in this article are included in the article's Creative Commons licence, unless indicated otherwise in a credit line to the material. If material is not included in the article's Creative Commons licence and your intended use is not permitted by statutory regulation or exceeds the permitted use, you will need to obtain permission directly from the copyright holder. To view a copy of this licence, visit http://creativecommons.org/licenses/by/4.0/. 


\section{Case presentation}

A 68-year-old man presented in November 2018 with severe orthopnea, breathlessness and cough for 2 weeks duration. Routine blood investigations including serum tumour marker levels were within normal range. Contrast-enhanced computed tomography (CECT) scan revealed a well-defined heterogeneously enhancing large anterior mediastinal soft tissue mass measuring $11.6 \times$ $11.3 \times 18 \mathrm{~cm}$ with loss of fat planes with mediastinal structures and central necrotic areas. The mass was abutting the diaphragm and extending to the right hemithorax (Fig. 1). A well-defined nodular lesion was also noted in the right lobe of the thyroid measuring $3.8 \times 3.7 \times 4.9$ $\mathrm{cm}$, however, no abnormal FDG uptake was observed on the PET scan. No metastatic lesion was identified elsewhere.

A CT-guided transthoracic core biopsy of the mediastinal mass was performed, which revealed a cellular spindle cell tumour of mesenchymal origin. However, definitive characterization could not be established as IHC markers were not performed on the biopsy specimen. Subsequently, the patient underwent a right anterolateral thoracotomy with excision of the anterior mediastinal mass and right hemithyroidectomy. Although the tumour was removed in toto, however, enbloc resection could not be obtained. Hence, the tumour was received for pathology evaluation as multiple large lobulated soft tissue pieces, the largest measuring 20x10x7 cm and smallest measuring $4.4 \times 2.8 \times 1 \mathrm{~cm}$. The tumour was soft to firm, grey-white, fleshy with few myxoid areas. Focal areas of necrosis, haemorrhage and calcification were also noted.

Histopathological examination revealed a spindle cell tumour with hypo and hypercellular areas due to collagenous stroma, which was arranged in fascicular, focal storiform and hemagio-pericytomatous vasculature pattern. (Fig. 2A \&B) There were areas of necrosis (Fig. $2 \mathrm{C}$ ), haemorrhage, hyalinization and myxoid change.
Tumour cells were oval to spindle-shaped and showed moderate to marked nuclear atypia and frequent mitotic activity ((8-12/10 HPF). (Fig. 2D) There was no invasion of vital neighbouring mediastinal structures. On Immunohistochemistry (IHC), the tumour cells were positive for CD34(strongly and diffusely; Fig. 3A) and Bcl-2 (weak and focal; Fig. 3A) along with focal desmin (Fig. $3 \mathrm{C}$ ), and S100 expression (Fig. 3E), in occasional rare tumour cells. IHC for EMA, SMA (Fig. 3D), and CD31 were negative. MIC-2 showed dot-like positivity. The possibility of a malignant peripheral nerve sheath tumour (MPNST) with heterologous rhabdomyosarcomatous differentiation (Triton tumour) versus malignant SFT was considered. There were no obvious rhabdomyoblasts and other markers for RMS besides Desmin (i.e., myogenin and Myo-D1) were negative. Additional IHC for STAT6 was carried out, which showed nuclear positivity expression of moderate-intensity in approximately $70 \%$ of tumour cells (Fig. 3F). Hence, confirming the diagnosis of an SFT with aberrant expression of S100 and Desmin. Because of the presence of an unusual histologic pattern of SFT and STAT6 positivity with necrosis, increased mitotic activity of $>4$ mitoses/ 10HPF, nuclear atypia, large tumour size $(20 \mathrm{cms})$, led to the classification of this tumour as a malignant giant SFT of the mediastinum.

The right thyroid lobe lesion showed a partly encapsulated tumour with micro and macro follicular arrangement. No definite nuclear features of papillary thyroid carcinoma were seen. No definite capsular or vascular invasion was seen. Features were consistent with that of a follicular adenoma. There was no evidence of lymph node or visceral metastasis elsewhere.

On follow-up, the patient developed local recurrence in the mediastinum (measuring $18 \times 16 \mathrm{cms}$ ) within 1 year after surgery and despite multi-modality treatment (Reexcision, Chemotherapy and Radiotherapy) succumbed within 14 months from point of initial presentation.

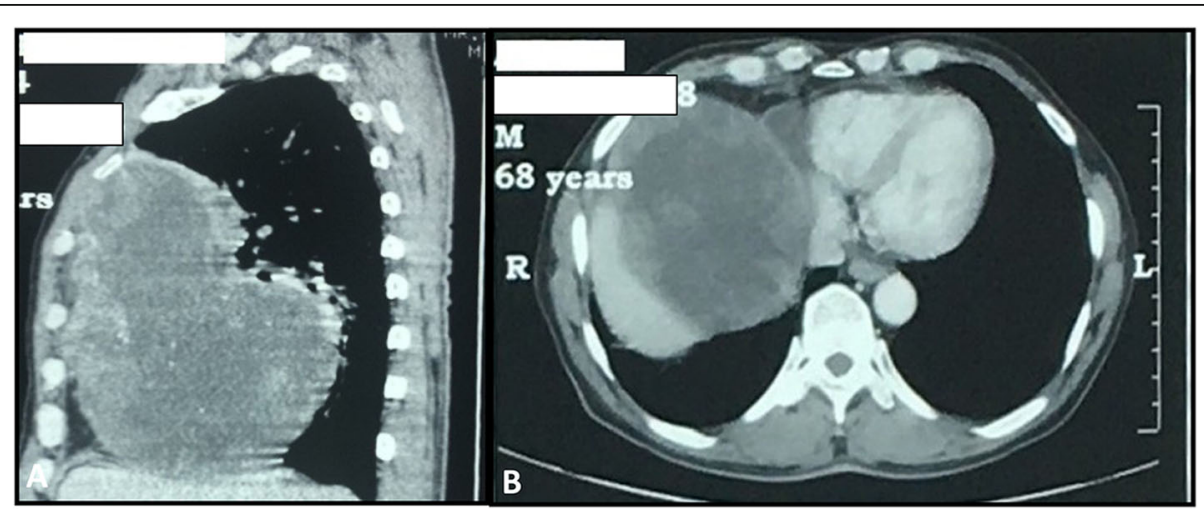

Fig. 1 Contrast enhanced CT scan of chest shows a large anterior mediastinal soft tissue mass with loss of fat planes, abutting diaphragm and extending to the right hemithorax with inhomogeneous areas of necrosis. (A Sagittal view \& B Mediastinal Window) 


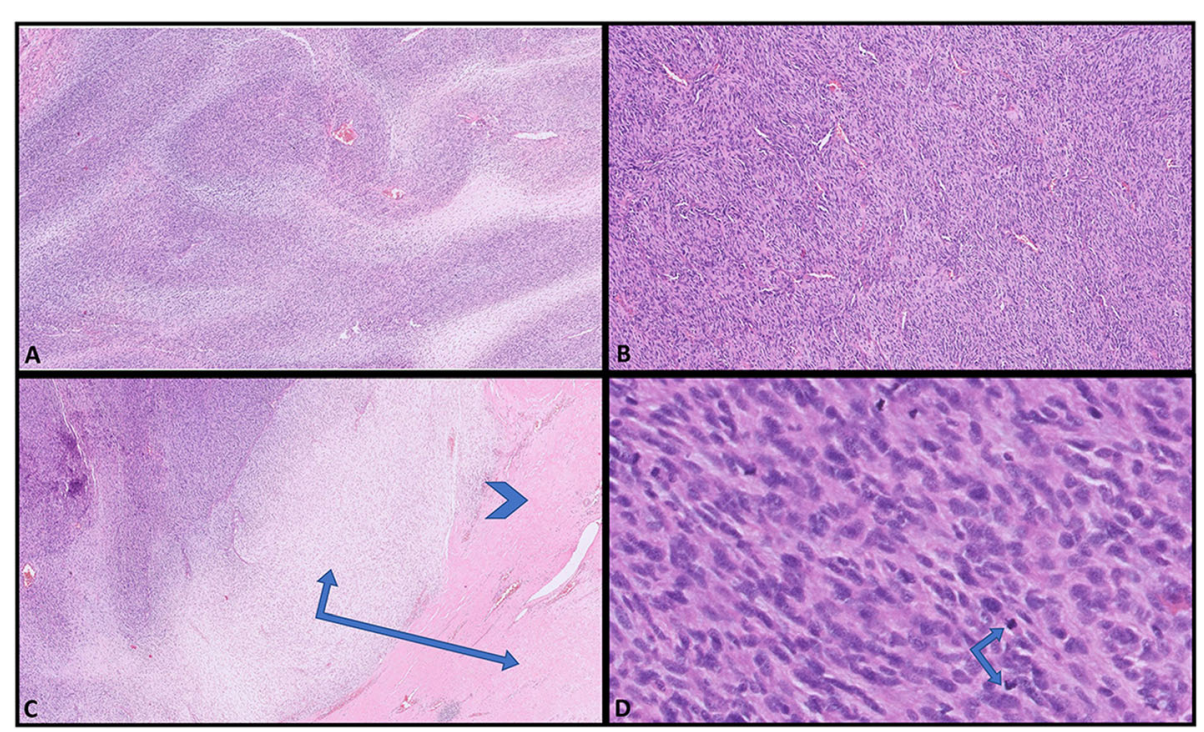

Fig. 2 Histological examination shows variable cellular spindle cell tumour (A H\&E; 40x) with prominent hemangiopericytomatous vasculature pattern ( $\mathbf{B}$ H\&E; 100x) and areas of necrosis [double arrowhead] and sclerotic bands (C H\&E; 100x). The tumour cells revealed marked nuclear atypia, hypercellularity and brisk mitosis (arrow) (D H\&E; 400x)

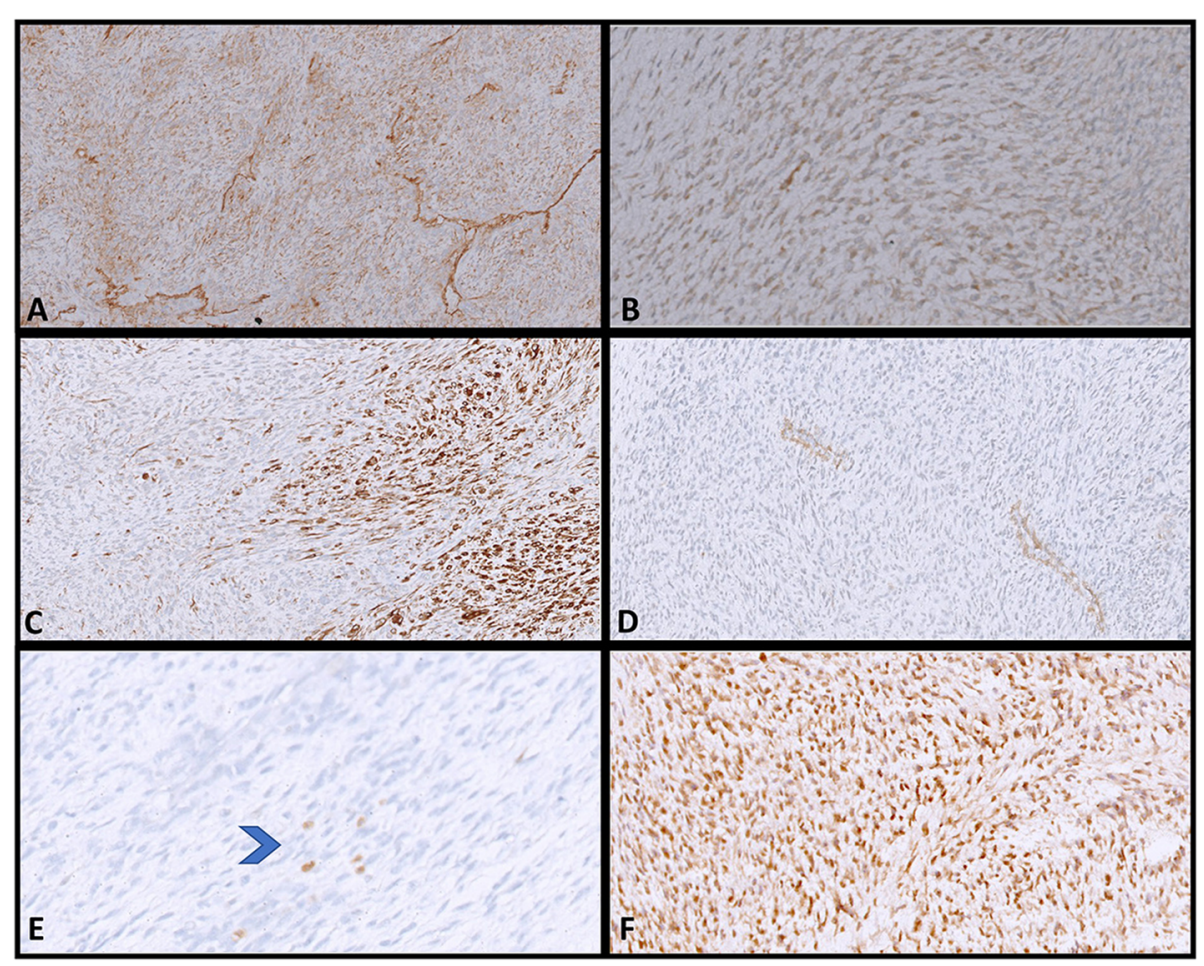

Fig. 3 Tumour cells showed diffuse immunopositivity for CD34, which had also highlighted staghorn vasculatures (A DAB; 200x), Weak staining for BCL-2. (B DAB; 200x). Besides focal immunostaining for desmin (C DAB; 200x) was noted, however, SMA was negative ((D DAB; 200x). Occasional cells were also positive for S-100 protein. (Arrow) (E DAB; 400 x) Strong and diffuse nuclear staining for STAT6 confirmed diagnosis of SFT(F DAB; 200X) 


\section{Discussion}

SFTs are mesenchymal tumours of intermediate malignant potential and are now believed to arise from CD34 positive dendritic mesenchymal cells (Zhang et al. 2017). They are usually composed of a patternless architecture with hemangio-pericytomatous like vasculature in a variably collagenous stroma (Demicco et al. 2020; Fletcher et al. 2013). CD34 and Bcl2 are highly characteristic IHCs for SFT (Demicco et al. 2020; Geramizadeh et al. 2016). But rarely EMA, SMA, keratin, desmin and S100 may come positive (Den Bakker et al. 2015; Leroy et al. 2001). Histologically, extrapleural SFT shares morphological features same as those of the pleural SFT. The diagnosis of extrapleural SFT is challenging, owing to its rarity, and requires an integrated approach that includes specific clinical, histological, IHC, and even molecular findings (Ronchi et al. 2018).

This particular case of the mediastinal tumour was very challenging to diagnose and a wide range of differentials diagnoses were considered ranging from type $\mathrm{A}$ thymoma, sarcomatoid mesothelioma, sarcomatoid carcinoma, to mesenchymal tumours like MPNST, leiomyosarcoma (LMS), rhabdomyosarcoma (RMS) and synovial sarcoma (SS). Due to negative epithelial marker i.e., EMA the possibility of thymoma, sarcomatoid mesothelioma and sarcomatoid carcinoma was unlikely. Rarely cytokeratin expression can be observed in SFT (Leroy et al. 2001). Although $\mathrm{Bcl} 2$ and MIC-2 positivity raised the option of SS, however diffuse CD34 positivity, in this case, ruled out its possibility. However, CD34 can be absent in approximately $5-10 \%$ of conventional SFT, especially in malignant and dedifferentiated forms (Yamada et al. 2019). Molecular testing for specific $t(X$; 18) (p11.2;q11.2) translocation for SS can be valuable adjunct in such scenario (Den Bakker et al. 2015). Further, despite focal Desmin positivity, diagnosis of LMS was unlikely in this case, as SMA was negative. Hence, MPNST with heterologous differentiation (due to focal S-100 and focal Desmin positivity) and malignant SFT (due to $\mathrm{CD} 34, \mathrm{Bcl} 2$ and Mic2 positivity) were the main differentials considered finally in this case. Further, there were no obvious rhabdomyoblasts or dedifferentiated areas in this particular case. So finally, the diagnosis of malignant SFT was established based on the expression of IHC for STAT6.

The discovery of NAB2(NGFI-A-binding protein 2) /STAT6(signal transducer and activator of transcription) fusion by next-generation sequencing studies has led to the discovery of nuclear expression of STAT6 protein in SFT, which is the most sensitive and specific marker for diagnosis of conventional and malignant SFT (Robinson et al. 2013). STAT 6 has a sensitivity of $98-100 \%$ for SFT with strong nuclear STAT6 taken to be a surrogate marker for NAB2-
STAT6 fusion gene (Koelsche et al. 2014; Yoshida et al. 2014; Doyle et al. 2014; Rekhi et al. 2017; Demicco et al. 2015). Demicco et al. studied a total of 2021 mesenchymal tumours for STAT6 expression, including 70 cases of MPNST and none were positive for STAT6 (Koelsche et al. 2014). Although nuclear positivity along with strong cytoplasmic staining for STAT6 s can be observed in some well-differentiated/ dedifferentiated liposarcoma, undifferentiated pleomorphic sarcoma and desmoid type fibromatosis; these STAT6 positive tumours were not included as a differential diagnosis in the index case. Hence, the use of STAT6 immunohistochemistry is a reliable surrogate for detection of SFT as demonstrated in this case when the diagnosis is inconclusive by conventional methods (Yoshida et al. 2014; Doyle et al. 2014).

SFT may show a variable clinical course with the majority of the patients being cured by surgical excision and the rest developing recurrences and metastases despite adjuvant therapy (Demicco et al. 2020; Fletcher et al. 2013). Mediastinal SFTs tend to follow a more aggressive course due to their complicated location that may hamper complete surgical resection (Fletcher et al. 2013; Den Bakker et al. 2015; De Raet et al. 2008). The prognosis is partially related to morphological features. Malignant SFT can arise de-novo or from malignant transformation of SFT (Yamada et al. 2019). The pathological criteria for malignancy as proposed by England et al. in SFT: Mitosis > 4 mitosis / 10hpf, high cellularity, cellular pleomorphism and necrosis were all present in the index case (England et al. 1989).

New models for predicting metastatic risk are now being proposed incorporating patient age $(<$ or $\geq 55$ years $)$, mitotic count $(0,1-3$ and $>4$ mitosis/10hpf), tumour size $(<5,5-<10,10-\leq 15,>15 \mathrm{~cm})$ with each factor assigned a score of $0-3$. The overall score predicts low (0-2 points), intermediate (3-4 points) and high (5-6 points) risk for metastasis. The four-tier model incorporates necrosis as an additional factor (Demicco et al. 2012, 2017). Our case developed local recurrence with adjuvant therapy adding little benefit and succumbed to the disease in a short time demonstrating poor survival and aggressive behaviour in case of malignant SFT at the uncommon location.

\section{Conclusion}

To conclude, despite rarity in the mediastinum, SFT can be recognized based on usual histomorphology and immunophenotypic profile. Use of specific markers i.e., STAT6 clinched the diagnosis in the index case. Diagnosis of malignant SFT can be challenging at an uncommon location, especially when there is a variable expression of various nonspecific IHC markers. 


\section{Abbreviations}

CT: Computed tomography; HPF: High power field;

IHC: Immunohistochemistry; LMS: Leiomyosarcoma; MPNST: Malignant peripheral nerve sheath tumour; RMS: Rhabdomyosarcoma; SFT: Solitary fibrous tumor; SS: Synovial sarcoma; STAT6: Signal transducer and activator of transcription

\section{Acknowledgements}

None.

\section{Authors' contributions}

RK conceived the idea. $A B$ and RK were the major contributor to the writing of the manuscript. RK, AB and JP diagnosed the case. AJ provided radiological review. RK was major contributor for critically revising the manuscript for important intellectual content. RK and $A B$ have given expert opinion and final approval of the version to be published. All authors read and approved the final manuscript.

\section{Funding}

This research received no specific grant from any funding agency in the public, commercial, or not-for-profit sectors.

\section{Availability of data and materials}

Not applicable.

\section{Declarations}

Ethics approval and consent to participate

Not applicable.

\section{Consent for publication}

Not applicable.

\section{Competing interests}

The authors declare that they have no competing interests.

\section{Author details}

'Department of Pathology, Tata Memorial Hospital, Homi Bhabha National Institute, Dr Ernest Borges Marg, Parel, Mumbai 400 012, India. ²Department of Radiology, Tata Memorial Hospital, Homi Bhabha National Institute, Mumbai, Maharashtra, India.

Received: 1 June 2021 Accepted: 2 August 2021

Published online: 14 October 2021

\section{References}

Chick JF, Chauhan NR, Madan R. Solitary fibrous tumours of the thorax: nomenclature, epidemiology, radiologic and pathologic findings, differential diagnoses, and management. AJR Am J Roentgenol. 2013;200(3):W238-48. https://doi.org/10.2214/AJR.11.8430.

De Raet J, Sacré R, Hoorens A, Fletcher C, Lamote J. Malignant giant solitary fibrous tumour of the mediastinum. J Thorac Oncol. 2008;3(9):1068-70. https://doi.org/10.1097/JTO.0b013e318183af5d.

Demicco EG, Fritchie KJ, Han A. Solitary fibrous tumour. In: WHO classification of Tumour Editorial Board. Soft tissues and Bone Tumours. 5th ed. Lyon: IARC Press; 2020. p. 104-8.

Demicco EG, Harms PW, Patel RM, Smith SC, Ingram D, Torres K, Carskadon SL, Camelo-Piragua S, McHugh JB, Siddiqui J, Palanisamy N, Lucas DR, Lazar AJ, Wang WL. An extensive survey of STAT6 expression in a large series of mesenchymal tumours. Am J Clin Pathol. 2015;143(5):672-82. https://doi. org/10.1309/AJCPN25NJTOUNPNF.

Demicco EG, Park MS, Araujo DM, Fox PS, Bassett RL, Pollock RE, Lazar AJ, Wang WL. Solitary fibrous tumour: a clinicopathological study of 110 cases and proposed risk assessment model. Mod Pathol. 2012;25(9):1298-306. https:// doi.org/10.1038/modpathol.2012.83.

Demicco EG, Wagner MJ, Maki RG, Gupta V, lofin I, Lazar AJ, Wang WL. Risk assessment in solitary fibrous tumours: validation and refinement of a risk stratification model. Mod Pathol. 2017:30(10):1433-42. https://doi.org/10.103 8/modpathol.2017.54
Den Bakker MA, Marx A, Mukai K, Ströbel P. Mesenchymal tumours of the mediastinum--part I. Virchows Arch. 2015;467(5):487-500. https://doi.org/10.1 007/s00428-015-1830-8

Doyle LA, Vivero M, Fletcher CD, Mertens F, Hornick JL. Nuclear expression of STAT6 distinguishes solitary fibrous tumour from histologic mimics. Mod Pathol. 2014;27(3):390-5. https://doi.org/10.1038/modpathol.2013.164.

England DM, Hochholzer L, McCarthy MJ. Localized benign and malignant fibrous tumours of the pleura. A clinicopathologic review of 223 cases [published correction appears in am J Surg Pathol. 1991;15(8):818]. Am J Surg Pathol. 1989;13(8):640-58. https://doi.org/10.1097/00000478-19890800000003.

Fletcher CDM, Bridge JA, Lee JC. Extrapleural solitary fibrous tumour. In: Fletcher CDM, Hogendoom PCW, Mertens F, editors. WHO classification of Tumours of soft tissues and bone. Lyon: IARC Press; 2013. p. 80-2.

Geramizadeh B, Marzban M, Churg A. Role of immunohistochemistry in the diagnosis of solitary fibrous tumour, a review. Iran J Pathol. 2016;11(3):195-203.

Koelsche C, Schweizer L, Renner M, Warth A, Jones DT, Sahm F, Reuss DE, Capper D, Knösel T, Schulz B, Petersen I, Ulrich A, Renker EK, Lehner B, Pfister SM, Schirmacher $P$, von Deimling A, Mechtersheimer G. Nuclear relocation of STAT6 reliably predicts NAB2-STAT6 fusion for the diagnosis of solitary fibrous tumour. Histopathology. 2014;65(5):613-22. https://doi.org/10.1111/ his.12431.

Leroy X, Copin MC, Petit S, Moukassa D, Gosselin B. Tumeur fibreuse solitaire pleurale maligne avec expression focale de cytokératine [malignant solitary fibrous tumour of pleura with focal expression of cytokeratin]. Ann Pathol. 2001;21(2):153-6.

Rekhi B, Shetty O, Tripathi P, Bapat P, Ramadwar M, Bajpai J, Puri A. Molecular characterization of a series of solitary fibrous tumours, including immunohistochemical expression of STAT6 and NATB2-STAT6 fusion transcripts, using reverse transcriptase (RT)-polymerase chain reaction (PCR) technique: an Indian experience. Pathol Res Pract. 2017;213(11):1404-11. https://doi.org/10.1016/j.prp.2017.08.011.

Robinson DR, Wu YM, Kalyana-Sundaram S, Cao X, Lonigro RJ, Sung YS, Chen CL, Zhang L, Wang R, Su F, lyer MK, Roychowdhury S, Siddiqui J, Pienta KJ, Kunju LP, Talpaz M, Mosquera JM, Singer S, Schuetze SM, Antonescu CR, Chinnaiyan AM. Identification of recurrent NAB2-STAT6 gene fusions in solitary fibrous tumour by integrative sequencing. Nat Genet. 2013;45(2):1805. https://doi.org/10.1038/ng.2509.

Ronchi A, Cozzolino I, Zito Marino F, Accardo M, Montella M, Panarese I, Roccuzzo G, Toni G, Franco R, De Chiara A. Extrapleural solitary fibrous tumour: a distinct entity from pleural solitary fibrous tumour. An update on clinical, molecular and diagnostic features. Ann Diagn Pathol. 2018;34:142-50. https://doi.org/10.1016/j.anndiagpath.2018.01.004.

Yamada Y, Kohashi K, Kinoshita I, Yamamoto H, Iwasaki T, Yoshimoto M, Ishihara S, Toda Y, Itou Y, Koga Y, Hashisako M, Nozaki Y, Kiyozawa D, Kitahara D, Inoue T, Mukai M, Honda Y, Toyokawa G, Tsuchihashi K, Matsushita Y, Fushimi F, Taguchi K, Tamiya S, Oshiro Y, Furue M, Nakashima Y, Suzuki S, Iwaki T, Oda Y. Clinicopathological review of solitary fibrous tumours: dedifferentiation is a major cause of patient death. Virchows Arch. 2019; 475(4):467-77. https://doi.org/10.1007/s00428-019-02622-9.

Yoshida A, Tsuta K, Ohno M, Yoshida M, Narita Y, Kawai A, Asamura H, Kushima R. STAT6 immunohistochemistry is helpful in the diagnosis of solitary fibrous tumours. Am J Surg Pathol. 2014;38(4):552-9. https://doi.org/10.1097/PAS. 0000000000000137.

Zhang L, Liu X, Li X, Tang Z, Shi C, Wang G. Diagnosis and surgical treatment of mediastinal solitary fibrous tumour. Asia Pac J Clin Oncol. 2017;13(5):e473-80. https://doi.org/10.1111/ajco.12594.

\section{Publisher's Note}

Springer Nature remains neutral with regard to jurisdictional claims in published maps and institutional affiliations. 